\title{
Mortality during heat waves in South Korea, 1991 to 2005: How exceptional was the 1994 heat wave?
}

\author{
Jan Kyselý, ${ }^{1, *}$, Jiyoung Kim² \\ ${ }^{1}$ Institute of Atmospheric Physics AS CR, Boční II 1401, 14131 Prague, Czech Republic \\ ${ }^{2}$ Korea Meteorological Administration, 45 Gisangcheong-gil Dongjak-gu, Seoul 156-720, South Korea
}

\begin{abstract}
The paper examines heat-related mortality in the population of South Korea between 1991 and 2005 and examines the extent to which the 1994 heat wave was unusual in terms of mortality impacts and recurrence probability. Most summer heat waves are found to be associated with enhanced mortality. However, the July to August 1994 heat wave was clearly exceptional, with the total death toll exceeding 3000 in South Korea. This value represents net excess mortality, as no displacement effect appeared after the hot summer season. Significantly elevated mortality occurred in all age groups, and an estimated $45 \%$ of victims were persons under $70 \mathrm{yr}$ of age. The relative increase in mortality was larger in children up to $14 \mathrm{yr}$ than in any other age group, and the mortality response was stronger in males than females, although males were less vulnerable during 'average' heat waves. The very large death toll ranks the 1994 heat wave over East Asia as among the worst weather-related disasters in this region. A climatological analysis reveals that the July to August 1994 heat wave might be considered an extremely rare event if temperature time series are assumed to be stationary. However, under a more realistic assumption of gradual warming related to global climate change, the recurrence probability of an event analogous to the 1994 heat wave is sharply rising for near-future time horizons. This emphasizes the need for an efficient heat-watchwarning system in this area, in order to reduce the human mortality impacts of heat waves.
\end{abstract}

KEY WORDS: Heat wave $\cdot$ Human mortality $\cdot$ East Asia $\cdot$ Extreme events $\cdot$ Climate change

\section{INTRODUCTION}

Evaluation of meteorological causes of extreme heat waves and assessments of their impacts on various fields of human activities, including human health, are topical issues in the scientific literature. The interest is at least partly related to the recently observed increases in the frequency, length and severity of high temperature extremes over many parts of the world (e.g. Frich et al. 2002, Alexander et al. 2006), as well as a growing concern of their future changes related to global warming (Meehl \& Tebaldi 2004, IPCC 2007) and associated adverse effects. In terms of mortality impacts, heat has been recognized as the most deadly among all atmospheric hazards (Sheridan \& Kalkstein 2004), and heat-related mortality has been reported in numerous locations and regions across North America (e.g. Whitman et al. 1997, Smoyer et al. 2000a,b, Curriero et al. 2002), Europe (Keatinge et al. 2000, Huynen et al. 2001, Laschewski \& Jendritzky 2002, Kyselý \& Huth 2004), Asia (Nakai et al. 1999, Tan et al. 2004, 2007, Choi et al. 2005) and Australia (Guest et al. 1999, Vaneckova et al. 2008).

The present paper examines mortality during heat waves in South Korea over the 15 yr period from 1991 to 2005, when daily mortality data are available. The country lies in a mild climate zone, with a mixture of continental and maritime influences leading to relatively cold winters and warm summers driven by the East Asian monsoon system. Hot weather over the Korean Peninsula in the summer months usually starts with expansion of a north-western Pacific high in late July, and is also closely associated with the end of the rainy period (so-called Changma) during late June to 
about the middle of July (Yihui \& Chan 2005). Variability of weather on synoptic time scales is large, and hot weather conditions occur almost every summer. The large seasonal temperature changes and high withinseason variability of weather cause the population to be prone to heat-related mortality.

A specific focus of the present study is directed towards the unusually severe heat waves that hit East Asia in 1994. Their association with mortality impacts in specific segments of the population has been described in several previous papers: Choi et al. (2005) found increased mortality in the population of Seoul (+626 deaths over the summer period in 1994), mainly among the elderly. An important role of enhanced ozone concentrations on modulating within-heat-wave differences in mortality was reported by Sung et al. (2001), and regional differences in city-specific threshold temperatures and magnitudes of heat-related mortality were evaluated by Kim et al. (2006a). Kim et al. (2006b) reported that the hot period with enhanced mortality in Seoul was closely associated with the prolonged drought in the region. Park \& Schubert (1997) also examined large-scale atmospheric circulation associated with the hot and dry weather, with respect to an anomalous evolution of the East Asian monsoon and unusually persistent stationary waves, extending from northern Europe over Eurasia during the summer of 1994.

Increasing trends in average temperature and temperature extremes have been observed in the area under study over recent decades. Mean temperature in South Korea has increased by about $1.5^{\circ} \mathrm{C}$ during the 20th century (more than twice that corresponding to global warming), which has been attributed mainly to the intensified greenhouse effect and rapid urbanization (Kwon 2005). The Korean Peninsula appears to be particularly responsive to possible anthropogenically induced climatic changes (Im et al. 2008). As the global mean surface temperature is projected to increase further in the 21st century, it is expected that Korea will be particularly vulnerable to climate change. According to Boo et al. (2004, 2006), daily temperatures over Korea are expected to increase by about $6^{\circ} \mathrm{C}$ between 1971 to 2000 and 2071 to 2100 ; Boo et al. (2006) also anticipate a sharp rise in the frequency and intensity of hot spells and droughts in the future.

The present paper is the first comprehensive study on the mortality impacts of heat waves in the population of South Korea. We focus on a comparison of the severe 1994 heat wave with other heat waves between 1991 and 2005, in terms of excess mortality, and estimate the recurrence probabilities associated with such an event for the near future, assuming an increase in summer temperatures related to global warming.

\section{DATA AND METHODOLOGY}

\subsection{Mortality data}

Daily data were processed on all-cause (total) mortality and mortality due to cardiovascular diseases (CVD; ICD-10 Codes I00-I99) in South Korea (population 47.3 million, as of December 2005) over the period from 1991 to 2005, stratified by gender and divided into 8 age groups. To account for long-term trends in mortality (related mainly to demographic and health care changes) and the seasonal and weekly cycles, the daily death counts must be standardized. We applied a slightly modified standardization procedure (used e.g. in Guest et al. 1999, Smoyer et al. 2000a and Whitman et al. 1997), based on calculating deviations of the observed number of deaths and the expected number of deaths (termed 'excess mortality' hereafter) for each day of the examined period, separately for total and CVD mortality and for each age group and gender.

The expected (baseline) number of deaths was computed so that it took into account:

- the long-term changes in mortality (decreasing number of deaths in age groups up to $59 \mathrm{yr}$ for males and $69 \mathrm{yr}$ for females, increasing number of deaths in age groups $60+\mathrm{yr}$ for males and $70+\mathrm{yr}$ for females), related to medical-technological progress and demographic changes associated with enhanced life expectancy and increasing percentage of the elderly in the population; total mortality between 1991 and 2005 increased slightly in females and were approximately levelled-off in males (Fig. 1);

- the annual cycle (lower mortality in late than early summer);

- the weekly cycle (higher/lower mortality on Mondays/ Sundays compared to the other days of the week; possible reasons for weekly variations in mortality are discussed by e.g. Wang et al. 2002).

Before calculating baseline mortality, days with very large accidents in South Korea between 1991 and 2005 (aviation and maritime disasters, a store collapse and fires: Table 1) and death tolls due to severe natural disasters (typhoons and floods), resulting in $>100$ accidental or disaster-related deaths each, were excluded from the database, in order to avoid their misleading effects on baseline mortality estimates.

Employing this approach, the expected number of deaths $M_{0}(y, d)$ for Year $y(y=1991, \ldots, 2005)$ and Day $d$ $(d=1, \ldots, 365)$ was set according to:

$$
M_{0}(y, d)=M_{0}(d) \times \mathrm{W}(y, d) \times \mathrm{Y}(y)
$$

where $M_{0}(d)$ denotes the mean daily number of deaths on Day $d$ in a year (computed from the mean annual cycle smoothed by $21 \mathrm{~d}$ running means); $\mathrm{W}(y, d)$ is a 

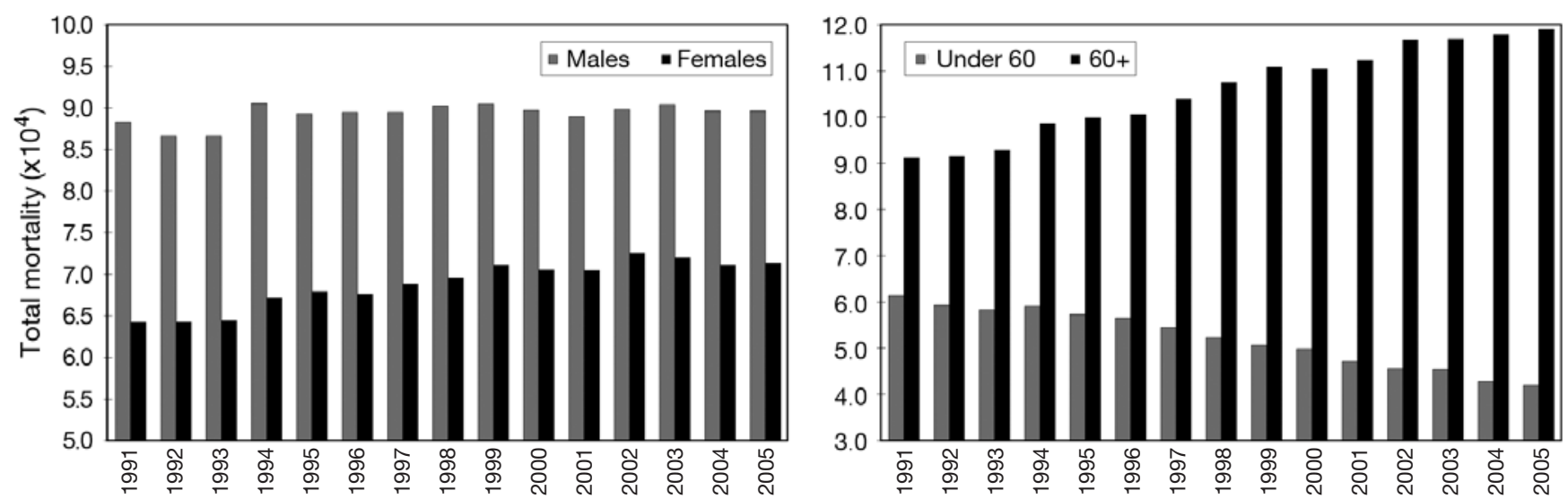

Fig. 1. Total mortality (April to November) in South Korea over the examined period according to sex (left) and age (right)

correction factor for the observed weekly cycle of mortality, calculated separately for Sunday, Monday and other working days (Tuesday to Saturday) and defined as a ratio of mean mortality (on a given day/days) to overall mean mortality; and $\mathrm{Y}(y)$ is a correction factor for the observed year-to-year changes in mortality, defined as a ratio of the mean number of deaths in a 3 yr period $<y-1, y+1>$ to the mean number of deaths over the whole analyzed period (for the first and last years, only data in Year $y$ are considered).

$\mathrm{W}(y, d)$ and $\mathrm{Y}(y)$ were calculated over the April to November period when the effects of epidemics of influenza/acute respiratory infections in the mortality data are negligible. When determining the mean annual cycle in mortality, we have found it necessary to exclude data for the summer of 1994 from the dataset because of the severe heat wave that occurred during this year. If data for the summer of 1994 were included in the estimation of the mean annual cycle,

Table 1. Large accidents and natural disasters in South Korea and/or affecting the population under study between 1991 and 2005 and the resulting death tolls (data from www.kma.go.kr/; Wikipedia [http://en.wikipedia.org/wiki/List_of_ accidents_and_disasters_by_death_toll, accessed March 5, 2008; http://en.wikipedia. org/wiki/List_of_natural_disasters_by_death_toll, accessed March 5, 2008])

\begin{tabular}{|lrl|}
\hline Date & Death toll & Event \\
\hline Accidents & & \\
29 Jun 1995 & 502 & Sampoong Department Store collapse (Seoul) \\
10 Oct 1993 & 292 & West Sea disaster (Seohae) \\
6 Aug 1997 & 228 & Korean Air Flight 801 (Guam) \\
18 Feb 2003 & 192 & Daegu Subway Fire (Daegu) \\
15 Apr 2002 & 128 & Air China Flight 129 (Busan) \\
28 Apr 1995 & 102 & Gas explosions by subway construction (Daegu) \\
Natural disasters & & \\
31 Jul-18 Aug 1998 & 324 & Massive rain, floods and landslides \\
30 Aug-1 Sep 2002 & 246 & Typhoon Rusa \\
12-13 Sep 2003 & 130 & Typhoon Maemi \\
25-27 Jul 2002 & 128 & Massive rain and floods \\
22-26 Aug 2002 & 103 & Typhoon Gladys \\
\hline
\end{tabular}

baseline mortality (in all years) would be influenced and artificially elevated.

In a similar fashion as for the weekly cycle, an artificial pattern present in the original daily mortality counts (each 5th, 10th, 15th, 20th, 25th and 30th value in a month elevated) - mainly during an earlier part of the records - was removed from the estimated excess mortality. This was achieved by calculating yearspecific multiplicative correction factors for the dates in a month. If not removed, the artificial pattern would have affected excess mortality estimates on a daily scale; its impact on aggregated excess mortality would decline with increasing length of the period. The Korea National Statistical Office was consulted on possible causes of the pattern, but the exact reason remains unknown.

The applied procedure allows for more robust estimates of excess mortality relative to a widely used comparison with a single previous summer season (as in Choi et al. 2005 for excess mortality in Seoul) or an application of $31 \mathrm{~d}$ moving averages (e.g. Rooney et al. 1998, Gosling et al. 2007), the latter being particularly inappropriate in cases when long heat waves are manifested in mortality data as in South Korea.

\subsection{Meteorological data}

Datasets of air temperature and heat index (HIAVG) (which captures joint effects of air temperature and humidity; see e.g. Steadman 1979, Smoyer et al. 2000b, Davis et al. 2002, 2003 for details) are based on measurements at 10 meteorological stations operated by the Korea 
Meteorological Administration (KMA) and covering South Korea (Fig. 2), carried out 4 times a day (at 03:00, 09:00, 15:00 and 21:00 h local time, LT). Average daily temperature (TAVG) and HIAVG were calculated as means of the 4 daily measurements. The stations were selected according to the following criteria: they were representative of the area, no important station moves and/or changes in measurement techniques occurred between 1971 and 2006, and the series for all variables were complete. Mean time series of each variable were calculated from data at the 10 stations, and they were used to characterize TAVG/HIAVG conditions in South Korea.

\subsection{Heat waves}

A number of definitions of heat waves appear in the literature. Herein, heat waves are defined as periods of $\geq 3$ d with HIAVG reaching or exceeding $33^{\circ} \mathrm{C}$ in the mean series for South Korea (corresponds to the $97 \%$

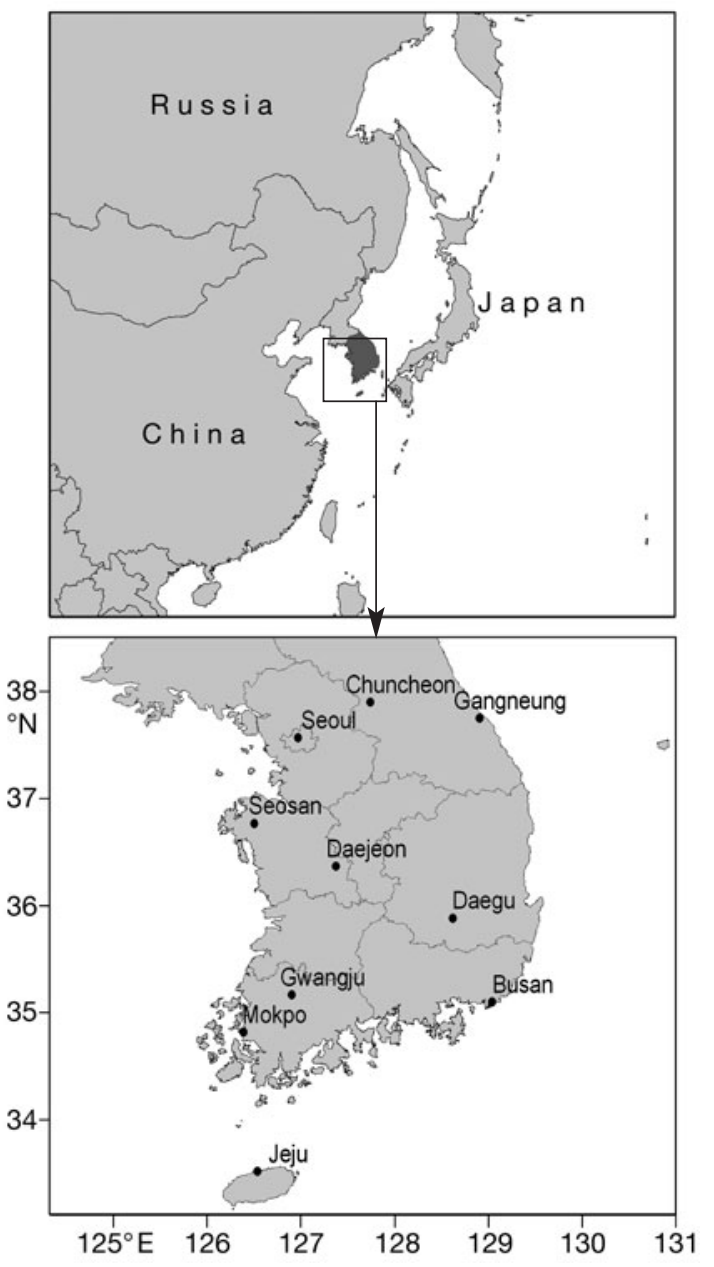

Fig. 2. Area under study (top) and locations of meteorological stations (bottom), South Korea quantile of the empirical distribution of HIAVG). A similar definition of heat waves, except for varied thresholds, is widely applied in climatological and biometeorological literature, with HIAVG or air temperature as the examined variable (e.g. Tan et al. 2007). The threshold corresponding to the $97 \%$ quantile was chosen as a useful compromise between possible lower (e.g. the $95 \%$ quantile) and higher thresholds (the 98 to $99 \%$ quantiles), because it delimits relatively severe heat waves, on the one hand, while still leading to a reasonably large number of events on the other (20 heat waves between 1991 and 2005; see Section 3). A preliminary analysis of the HIAVG-excess mortality relationship also revealed that both all-cause and CVD mortality tend to rise when HIAVG exceeds around $33^{\circ} \mathrm{C}$ (Fig. 3).

The analysis remains largely unchanged with alternative definitions of heat waves that have modified HIAVG thresholds and/or definitions of heat waves as periods with TAVG reaching or exceeding a high threshold in TAVG solely (set to $27^{\circ} \mathrm{C}$ according to the results of Kim et al. 2006a, as the lowest among cityspecific threshold temperatures above which heatrelated mortality appears in South Korea), except that
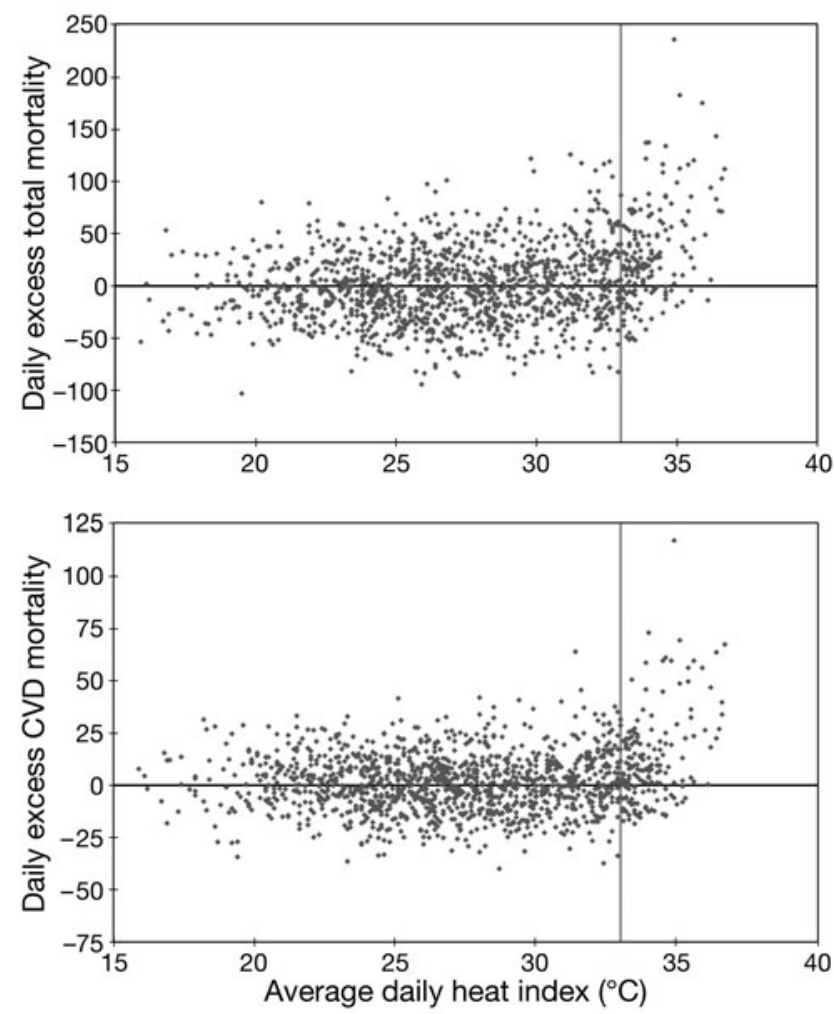

Fig. 3. Scatter-plots of departures of total (top) and cardiovascular disease (CVD; bottom) mortality against average daily heat index in the summer, from 1991 to 2005. The threshold value of $33^{\circ} \mathrm{C}$ used in the definition of heat waves is marked by a vertical line 
heat-related mortality is generally less pronounced when effects of high humidity are not taken into account. The more direct link of excess mortality to HIAVG than to air temperature is also in accord with results reported for the population of Seoul by Choi et al. (2005). We note that the definition using a constant threshold is useful in the present analysis of mortality, but it may be inappropriate in data referring to periods with a 'mean' climate different from the reference one (Davis et al. 2003).

As the relationship between heat waves and excess mortality was found to be better expressed (in terms of relative mortality increases) for unlagged data than for lags of 1 to $2 \mathrm{~d}$ after weather events - similar to findings in several other studies for various regions (e.g. Keatinge et al. 2000, Curriero et al. 2002, Hajat et al. 2002, Vaneckova et al. 2008)unlagged relationships were evaluated and are discussed.

\subsection{Stochastic time series model for daily temperature}

In order to estimate recurrence probabilities associated with an event analogous to the 1994 heat wave, we made use of long artificial time series of TAVG simulated by a first-order autoregressive model (AR[1]). The AR(1) models provide characteristics of heat waves and temperature threshold exceedances that are generally in a good agreement with observations in midlatitude areas (e.g. Mearns et al. 1984, Macchiato et al. 1993, Colombo et al. 1999). Several variants of the AR(1) models exist; in the present paper, we apply a model in which the seasonal cycle of TAVG is considered to be a deterministic part and only deviations from this cycle are simulated as a stochastic component, similar to the approach used by Macchiato et al. (1993).

In the first experiment ('present climate'), parameters of the model (mean, variance and the first-order autocorrelation coefficient for TAVG) are estimated from the mean temperature series for South Korea between 1971 and 2000. The AR(1) model is then used to generate 10000 artificial time series of TAVG corresponding to the months of May to September and the reference period (1971 to 2000).

In the second experiment ('climate change scenario'), a gradual warming of $0.04^{\circ} \mathrm{C} \mathrm{yr}^{-1}$ between 2001 and 2060 is assumed (see Section 3.3). The other parameters of the AR(1) model are kept unchanged in time, and 50000 artificial series of TAVG corresponding to the May to September periods between 2001 and 2060 are generated.

The experiments with the stochastic model are evaluated in Section 3.3.

\section{RESULTS}

\subsection{Mortality during heat waves in South Korea, 1991 to 2005}

The introduced definition leads to a count of 20 heat waves between 1991 and 2005, with a mean annual duration of $9.3 \mathrm{~d}$. Excess total mortality is positive during all except 2 of the heat waves, and the mortality increase is significant at $p=0.05$ in 11 out of 20 heat waves (Table 2). For CVD mortality, relative increases during heat waves are less often statistically significant (owing to considerably smaller sample sizes), but, for the most severe heat waves, they tend to be more pronounced compared to all-cause mortality (Fig. 4). If averaged over all heat wave days, mean relative excess total mortality is $+5.9 \%$, which corresponds to around 35 to 40 excess deaths daily on average. Respective values for CVD mortality are $+9.0 \%$ and around 12 excess deaths daily (Table 3 ). The mortality increases during heat waves are more pronounced among the elderly (persons aged 70+ yr). It should be noted, however, that positive excess mortality during heat waves also prevails in age groups from 0 to 14 and 15 to 59 yr (see also results for the 1994 heat wave below).

Mortality impacts are usually more pronounced in females than in males, which is observed in the total population (all ages), as well as in the elderly, if mean excess mortality during all heat waves is examined (Table 3). Averaged over the heat wave days, mean relative excess total mortality is significantly larger in females $(+6.8 \%)$ than in males $(+5.2 \%)$ at $\mathrm{p}=0.05$, according to the dependent samples $t$-test, as well as the Wilcoxon signed-rank test. However, if only the most severe heat waves are involved in the sample, excess mortality is often larger in males than in females. This may indicate that females are generally more susceptible to 'moderate' heat stress (e.g. due to pre-existing health problems), but during 'severe' heat waves males become increasingly sensitive and vulnerable to hot weather conditions.

\subsection{The 1994 heat waves and their mortality impacts}

The July/August 1994 heat wave was exceptional in its meteorological characteristics, as well as its human mortality impacts. Specific features of the summer of 1994 were a gradual warming during the last decade of June and the first decade of July, and an onset of persistent very hot and dry weather under a stationary anticyclone lasting almost continually for the 6 wk following 8 July (Fig. 5). According to the heat wave definition, the hot weather was split by 
Table 2. Meteorological characteristics and mortality impacts of heat waves in the population of South Korea, 1991 to 2005 . Temperature and heat index values refer to the means for South Korea. \%: relative mortality increase; n: the number of excess deaths; *excess mortality significantly different from zero at $\mathrm{p}=0.05$. Significance of excess mortality was computed using the standardized normal deviate $z$ obtained by dividing excess mortality by the square root of expected deaths (e.g. Sartor et al. 1995); excess mortality is significantly different from zero at $p=0.05$ when $|z|>1.96$. LT: local time. Bold: 1994 heat waves

\begin{tabular}{|c|c|c|c|c|c|c|c|c|c|}
\hline \multirow[t]{3}{*}{ Dates } & \multirow{3}{*}{$\begin{array}{l}\text { Length } \\
\text { (d) }\end{array}$} & \multirow{3}{*}{$\begin{array}{c}\text { Maximum } \\
\text { daily } \\
\text { temperature } \\
\text { at 15:00 h LT } \\
\left({ }^{\circ} \mathrm{C}\right)\end{array}$} & \multirow{3}{*}{$\begin{array}{c}\text { Maximum } \\
\text { average } \\
\text { daily } \\
\text { temperature } \\
\left({ }^{\circ} \mathrm{C}\right)\end{array}$} & \multirow{3}{*}{$\begin{array}{c}\text { Maximum } \\
\text { daily } \\
\text { heat index } \\
\text { at } 15: 00 \mathrm{~h} \mathrm{LT} \\
\left({ }^{\circ} \mathrm{C}\right)\end{array}$} & \multirow{3}{*}{$\begin{array}{l}\text { Maximum } \\
\text { average } \\
\text { daily heat } \\
\text { index } \\
\left({ }^{\circ} \mathrm{C}\right)\end{array}$} & \multicolumn{4}{|c|}{ _Mortality } \\
\hline & & & & & & \multicolumn{2}{|c|}{ Total } & \multicolumn{2}{|c|}{ CVD } \\
\hline & & & & & & $(\%)$ & (n) & $(\%)$ & (n) \\
\hline 21-23 Jul 1992 & 3 & 31.3 & 27.9 & 36.5 & 33.4 & 1.5 & 26 & 9.3 & 39 \\
\hline 28-30 Jul 1992 & 3 & 32.4 & 28.5 & 37.9 & 34.4 & 5.5 & $99^{*}$ & 4.9 & 22 \\
\hline 8 Jul-9 Aug 1994 & 33 & 35.4 & 30.4 & 40.9 & 36.7 & 15.1 & $3027^{*}$ & 26.8 & $1380^{*}$ \\
\hline 11-17 Aug 1994 & 7 & 33.7 & 29.8 & 39.2 & 35.5 & 7.6 & $323^{*}$ & 15.1 & $161^{*}$ \\
\hline 31 Jul-8 Aug 1995 & 9 & 32.3 & 28.8 & 37.7 & 34.6 & 0.8 & 42 & -1.6 & -22 \\
\hline 12-18 Aug 1995 & 7 & 33.6 & 29.4 & 40.0 & 36.1 & 2.0 & 85 & 1.8 & 19 \\
\hline 28 Jul-4 Aug 1996 & 8 & 33.5 & 29.1 & 39.3 & 35.2 & 4.9 & $243^{*}$ & 3.5 & 39 \\
\hline 8-14 Aug 1996 & 7 & 33.7 & 28.9 & 38.7 & 34.5 & 0.4 & 16 & -1.2 & -12 \\
\hline 21-25 Jul 1997 & 5 & 32.5 & 28.3 & 38.4 & 34.3 & 6.3 & $195^{*}$ & 4.8 & 33 \\
\hline 28 Jul-3 Aug 1997 & 7 & 31.9 & 28.1 & 38.0 & 34.1 & 1.1 & 50 & -1.5 & -14 \\
\hline 3-8 Aug 1998 & 6 & 30.7 & 28.3 & 37.3 & 34.6 & 4.4 & $164^{*}$ & 2.1 & 17 \\
\hline 8-11 Aug 1999 & 4 & 32.5 & 28.4 & 38.6 & 34.1 & 6.9 & $177^{*}$ & 14.3 & $79^{*}$ \\
\hline 18-21 Jul 2000 & 4 & 31.4 & 28.6 & 36.8 & 33.9 & -1.6 & -40 & -1.9 & -11 \\
\hline 22 Jul-4 Aug 2001 & 14 & 33.1 & 29.2 & 38.8 & 35.3 & 2.2 & $195^{*}$ & 1.1 & 22 \\
\hline 6-8 Aug 2001 & 3 & 32.3 & 28.0 & 37.6 & 33.6 & -4.1 & -78 & -2.6 & -11 \\
\hline 21-23 Jul 2004 & 3 & 32.7 & 28.4 & 37.7 & 33.7 & 8.0 & $151^{*}$ & 17.1 & $71^{*}$ \\
\hline 28-30 Jul 2004 & 3 & 33.0 & 28.6 & 37.8 & 33.8 & 3.9 & 74 & -1.8 & -8 \\
\hline 6-10 Aug 2004 & 5 & 32.4 & 28.3 & 37.2 & 33.3 & 3.9 & $124^{*}$ & 7.5 & $51^{*}$ \\
\hline 4-6 Aug 2005 & 3 & 33.0 & 29.0 & 37.7 & 34.3 & 4.5 & $86^{*}$ & 8.4 & 34 \\
\hline 12-17 Aug 2005 & 6 & 32.3 & 28.6 & 37.9 & 34.2 & 2.0 & 76 & 3.9 & 32 \\
\hline
\end{tabular}

a moderate cooling on 10 August (when Korea was partly affected by Typhoon Doug, which moved to the Yellow Sea, and precipitation was recorded between the afternoon of 10 August and the morning of 11 August) into 2 separate events: the July/August

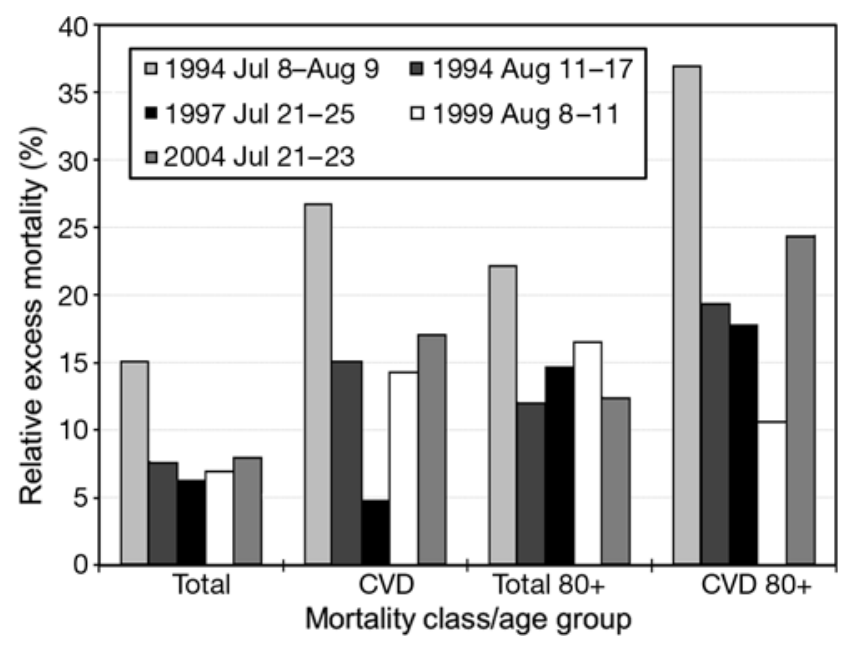

Fig. 4. Relative excess total mortality and cardiovascular disease (CVD) mortality during 5 severe heat waves for the whole population and the most susceptible part $(80+\mathrm{yr})$. The increase in percent is relative to baseline mortality estimated for a given heat wave heat wave (8 July to 9 August) and the August heat wave (11 to 17 August).

The July/August 1994 heat wave was by far the longest and most severe heat wave that has been observed over the Korean Peninsula since at least 1942, but also very likely the most severe in the entire 20th century (KMA 1990, Choi 2004). Its duration was $33 \mathrm{~d}$ (the second longest heat wave from 1991 to 2005 lasted $14 \mathrm{~d}$ ), and the maximum daily temperature at 15 LT reached $35.4^{\circ} \mathrm{C}$ in the mean series for South Korea, which is almost $2^{\circ} \mathrm{C}$ higher than during any other heat wave since 1991. The HIAVG was record-breaking, too: among the 20 greatest HIAVG values between 1991 and 2005, 15 occurred during the July/August 1994 heat wave, 3 during the following August 1994 heat wave, and only 2 on other days.

Table 3. Mean relative excess mortality on heat wave days from 1991 to 2005. CVD: cardiovascular disease

\begin{tabular}{|lccccc|}
\hline Mortality & $\begin{array}{c}\text { Whole } \\
\text { population } \\
(\%)\end{array}$ & $\begin{array}{c}\text { Males } \\
(\%)\end{array}$ & $\begin{array}{c}\text { Females } \\
(\%)\end{array}$ & $\begin{array}{c}\text { Males } \\
70+ \\
(\%)\end{array}$ & $\begin{array}{c}\text { Females } \\
70+ \\
(\%)\end{array}$ \\
\hline Total & 5.87 & 5.17 & 6.80 & 6.00 & 8.39 \\
CVD & 9.04 & 8.07 & 9.88 & 11.87 & 11.06 \\
\hline
\end{tabular}



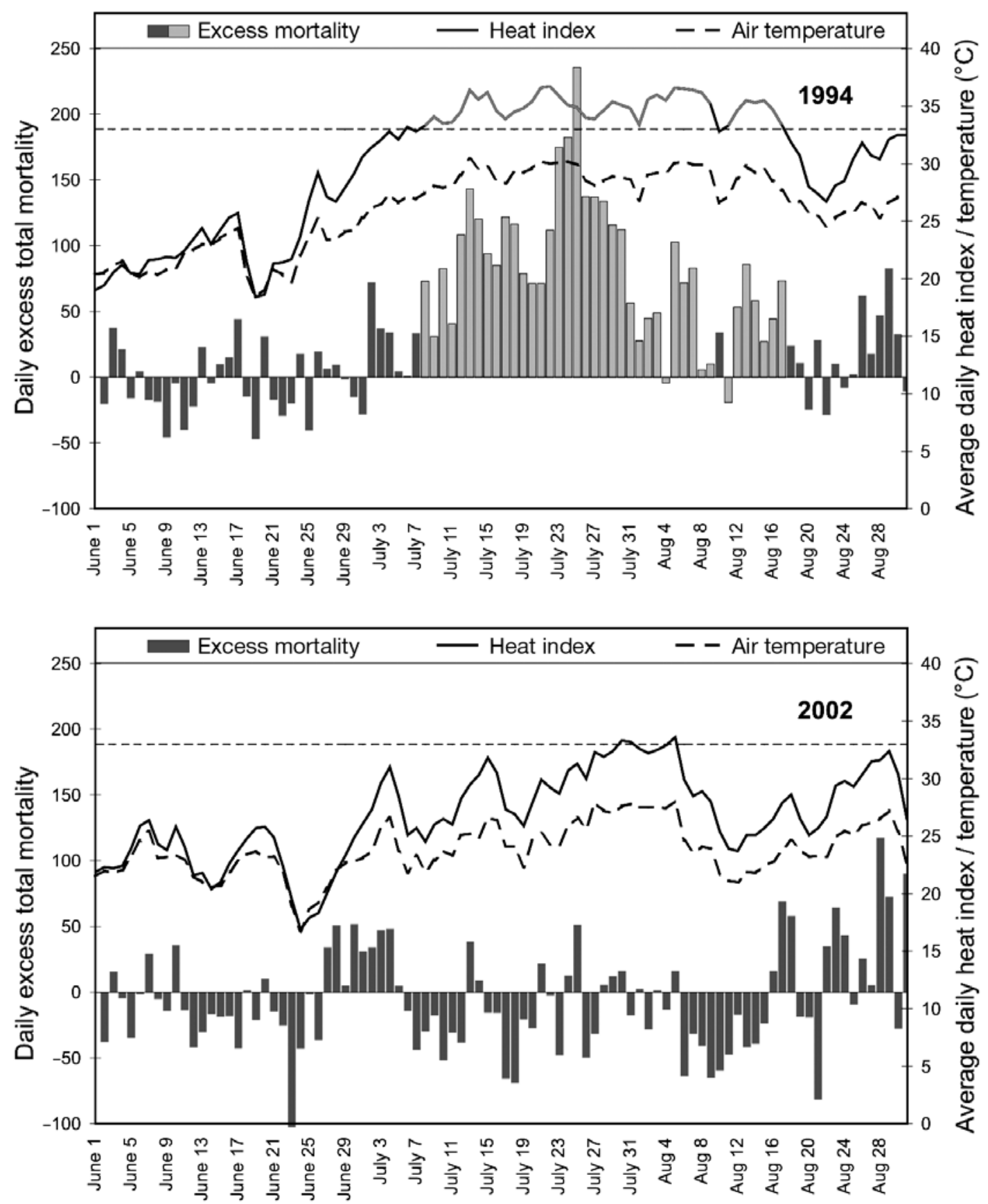

Fig. 5. Excess total mortality (bars) and average daily heat index/air temperature in the mean series for South Korea during the summer of 1994 (top panel); the 2 heat waves are marked in grey. Horizontal line: threshold for the heat index applied in the definition of heat waves. For comparison, excess total mortality and average daily heat index/air temperature in a summer without heat waves (2002) are plotted (bottom panel). The scale of the $y$-axis has been kept identical in both graphs

With respect to mortality impacts, the July/August 1994 heat wave was also extraordinary: the total death toll is estimated to have exceeded 3000 (3027; 95\% CI: 2750 to 3305 ) in the overall population (Table 2), a value which is an order of magnitude larger than in any other heat wave. Even more surprisingly, the second deadliest heat wave in the period between 1991 and 2005 was that in August 1994, which followed very shortly afterward, with $>300$ additional excess deaths $(323 ; 95 \%$ CI: 195 to 450$)$. If the separation of the 2 events by the moderate cooling on 10 August is disregarded and the whole period from 8 July to 17 August is considered together, the estimated death toll is 3384 (95\% CI: 3075 to 3694 ). We note that the reported 
excess mortality is almost independent of the settings of the standardization procedure applied (Section 2.1): slightly modified approaches to estimating baseline mortality (differing in the length of the window over which the mean annual cycle is smoothed; in whether accidental deaths are excluded from the estimation of baseline mortality or not; in the way the long-term trend is removed; etc.) all lead to between 3300 and 3400 excess deaths. This value also agrees with a firstguess estimate considering mortality over a certain part of the year compared with that period in previous and following years (between 3100 and 4200 excess deaths).

Above 100 excess deaths daily were recorded on each day from 22 to 30 July 1994 . The daily excess mortality was most exacerbated in a $3 \mathrm{~d}$ period after the heat wave peak on $22 \mathrm{July}$; around 600 excess deaths occurred between 23 and 25 July. Relative increases in CVD mortality exceeded those in total mortality, and over the period from 8 July to $17 \mathrm{Au}$ gust, +1578 excess deaths (95\% CI: 1422 to 1735 ) due to CVD occurred (which corresponds to a $25 \%$ relative increase).

Another very conspicuous feature of the 1994 heat wave is that significant excess mortality was observed in all age groups, including children (0 to $14 \mathrm{yr}$ ) and people aged 15 to $59 \mathrm{yr}$ (Table 4). The relative mortality increase was particularly large for children (+27.5\%; 183 excess deaths, $95 \%$ CI: 133 to 234$)$, and, of the total estimated death toll of the heat wave, around $45 \%$ of excess deaths were people under $70 \mathrm{yr}$ of age. This means that not only among the elderly, but also for younger and middle-aged people, the number of victims was higher than in any of the large accidents or natural disasters over the examined period (note that all events listed in Table 1 led to a disproportionately large death toll in people of productive age).

A comparison of mortality impacts of the 1994 heat waves in males and females (Table 4) confirms that the response to severe heat was larger in males (in all age groups except for 70 to $79 \mathrm{yr}$ olds), although males are generally less vulnerable to heat than females in 'average' heat waves. Excess total mortality during the July/August 1994 heat wave was significantly positive in all age groups, even if the data are stratified by gender (Table 4), so the whole population was affected. Noteworthy is also the fact that amidst all age groups and in both males and females, the relative increase was largest in children up to $14 \mathrm{yr}$ of age. In absolute numbers, a much larger portion of victims in age groups of up to 70 yr were males (+980 excess deaths compared to +355 excess deaths in females), while a reverse pattern appears in those aged $70+$ yr (Table 4).

No signs of a mortality displacement effect (lower than expected mortality after some heat waves due to the fact that heat often kills people whose health has been compromised and who would have soon died anyway even in the absence of stressful weather; Huynen et al. 2001, Kyselý 2004, Gosling et al. 2007) appear after the 1994 heat waves. In fact, positive values of excess daily total mortality persisted on most days until the end of August (+246 excess deaths, 18 to 31 August), despite a moderate cooling, as well as during most of September (+448 excess deaths). It might even be speculated that these excess deaths are to some extent related to the very unusual summer heat waves (due to health impairments resulting in deaths after several weeks), but they definitely demonstrate that no harvesting effect was in action in mortality values after the 1994 heat wave. Mortality was also close to usual levels in the winter of 1994/1995.

\subsection{The 1994 heat wave - a climatological perspective}

According to extreme temperature records in South Korea (KMA 1990, Choi 2004), the 1994 heat wave seems to be an exceptional event for the 20th century. Using long stochastically generated time series of daily temperature (Section 2.4), a recurrence probability of the most severe part of the heat wave, a $21 \mathrm{~d}$ spell with TAVG $\geq 28.0^{\circ} \mathrm{C}$ (11 to 31 July) can be estimated. The very long uninterrupted sequence of days above such

Table 4. Excess total mortality in individual population groups during the 1994 heat waves. \%: relative mortality increase; $\mathrm{n}$ : number of excess deaths; ${ }^{*}$ excess mortality significant at $\mathrm{p}=0.05$ in a given age group; $\mathrm{M}$ : males; F: females

\begin{tabular}{|c|c|c|c|c|c|c|c|c|c|c|c|c|}
\hline \multirow[t]{2}{*}{ Dates } & \multirow{2}{*}{$\begin{array}{l}\text { Length } \\
\text { (d) }\end{array}$} & \multirow[t]{2}{*}{ Group } & \multicolumn{2}{|c|}{$0-14$ yr } & \multicolumn{2}{|c|}{$15-59$ yr } & \multicolumn{2}{|c|}{$60-69 \mathrm{yr}$} & \multicolumn{2}{|c|}{$70-79$ yr } & \multicolumn{2}{|c|}{$80+y r$} \\
\hline & & & $(\%)$ & (n) & $(\%)$ & (n) & $(\%)$ & (n) & $(\%)$ & (n) & $(\%)$ & (n) \\
\hline \multirow[t]{3}{*}{8 Jul-9 Aug 1994} & \multirow[t]{3}{*}{33} & $\mathrm{M}+\mathrm{F}$ & 27.5 & $183^{*}$ & 9.4 & $676^{*}$ & 13.0 & $476^{*}$ & 15.3 & $706^{*}$ & 22.2 & $896^{*}$ \\
\hline & & M & 28.7 & $118^{*}$ & 10.2 & $540^{*}$ & 14.1 & $322^{*}$ & 14.3 & $340^{*}$ & 26.6 & $342^{*}$ \\
\hline & & $\mathrm{F}$ & 25.6 & $65^{*}$ & 7.2 & $136^{*}$ & 11.3 & $154^{*}$ & 16.3 & $366^{*}$ & 20.1 & $554^{*}$ \\
\hline \multirow[t]{3}{*}{ 11-17 Aug 1994} & \multirow[t]{3}{*}{7} & $\mathrm{M}+\mathrm{F}$ & -5.5 & -8 & 10.4 & $158^{*}$ & 1.5 & 12 & 3.9 & 38 & 12.0 & $101^{*}$ \\
\hline & & $\mathrm{M}$ & 13.6 & 12 & 10.7 & $121^{*}$ & 5.1 & 24 & 3.1 & 15 & 16.7 & $46^{*}$ \\
\hline & & $\mathrm{F}$ & -34.3 & -19 & 9.4 & 38 & -4.5 & -13 & 4.8 & 23 & 9.8 & $56^{*}$ \\
\hline
\end{tabular}


a high threshold is unprecedented in the mean series for Korea; the second longest spell between 1971 and 2006 lasted $12 \mathrm{~d}$ only.

Under the simplified assumption of a stable 'present climate', with parameters of the AR(1) model estimated from data between 1971 and 2000, the recurrence period associated with a run of at least $21 \mathrm{~d}$ with TAVG $\geq 28.0^{\circ} \mathrm{C}$ is around $430 \mathrm{yr}$. For comparison, a recurrence period of spells lasting at least $15 \mathrm{~d}$ is estimated to be around $63 \mathrm{yr}$, and of spells with the duration at least 10 (5) d around 14 (3) yr. The latter appear to be quite realistic values when compared with the observed series (the comparison is feasible owing to the relatively high frequency of such events) and indicate the reasonably good performance of the stochastic model: 3 (12) spells of at least 10 (5) consecutive days with TAVG $\geq 28.0^{\circ} \mathrm{C}$ occurred between 1971 and 2006, which corresponds to their recurrence interval of 12 (3) yr.

Taking into account a possible climate change projection of summer temperature increase in South Korea for the mid-21st century (2031 to 2060), which considers an increase in mean temperatures of 2.0 to $2.5^{\circ} \mathrm{C}$ relative to the 1971 to 2000 reference period (Bae et al. 2008), analogous simulations were carried out assuming a warming trend of $0.04^{\circ} \mathrm{C}^{\mathrm{yr}^{-1}}$ between 2001 and 2060. This leads to an increase in mean temperature of $2.0^{\circ} \mathrm{C}$ in 2050 compared to that in 1971 to 2000. Although the range of uncertainty in future climate change scenarios is large, the assumed warming is in good agreement with some other studies for the Korean Peninsula (Boo et al. 2004, Im et al. 2008), as well as with the trend observed over recent decades if extrapolated towards future.

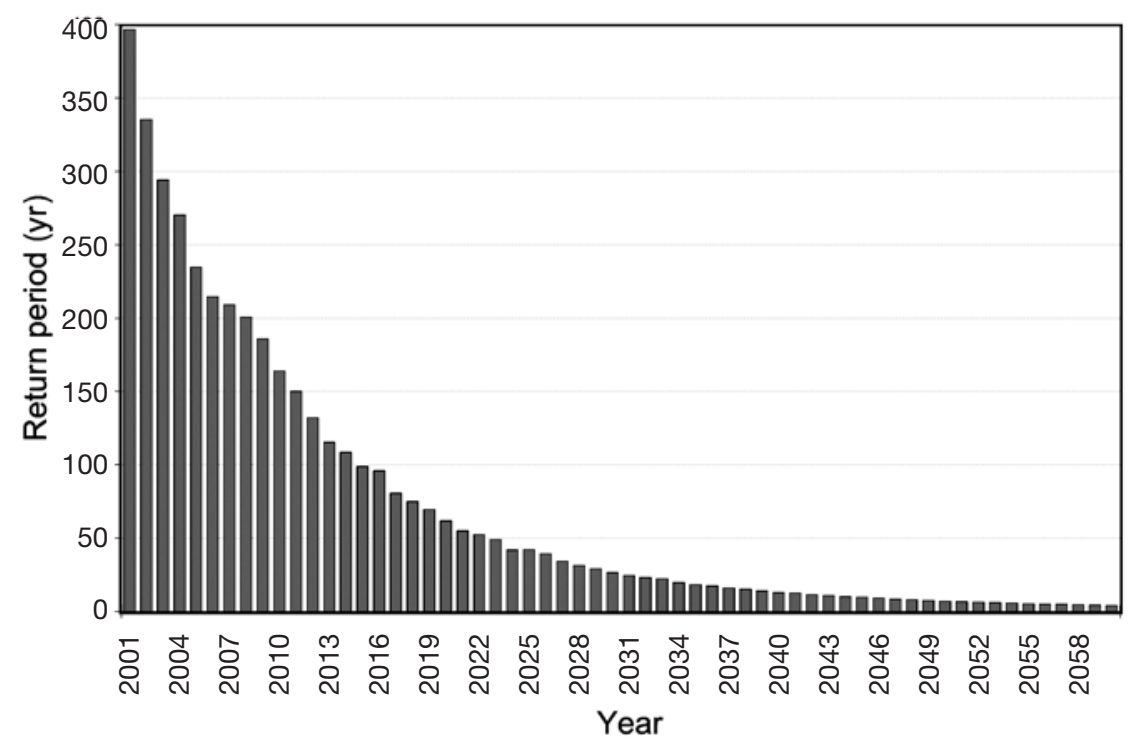

Fig. 6. Changes in the recurrence period of at least $21 \mathrm{~d}$ spells of days with average daily temperatures (TAVG) $\geq 28^{\circ} \mathrm{C}$, based on simulations with the AR(1) model assuming a warming trend of $0.04^{\circ} \mathrm{C} \mathrm{yr}^{-1}$ between 2001 and 2060
The recurrence interval of a spell of at least $21 \mathrm{~d}$ with TAVG $\geq 28^{\circ} \mathrm{C}$ sharply decreases even under the relatively moderate warming assumed in this experiment (the recurrence periods simulated for individual years between 2001 and 2060 are plotted in Fig. 6). If averaged between 2021 and 2030 (2041 and 2050), the recurrence period declines to around $38(9.3) \mathrm{yr}$ compared to the estimated $430 \mathrm{yr}$ in the 1971 to 2000 reference period. In other words, a spell with a probability comparable to the one observed in 1994 over the 1971 to 2000 period has a length of 30 (39) d in the $2020 \mathrm{~s}$ (2040s). It should also be emphasized that these projections are for the relatively near future, and, if the warming trend continues, increases in the frequency of severe heat waves will become much more pronounced in the second half of the 21st century.

\section{DISCUSSION AND CONCLUSIONS}

The study presents a first comprehensive analysis of mortality impacts of heat waves in the population of South Korea, with a focus on the unusually long 1994 heat wave. The effects of the July/August 1994 heat wave on mortality were exceptionally severe: $>3000$ excess deaths occurred during the 8 July to 9 August period. Mortality was significantly elevated in all age groups, and a surprisingly large percentage of victims (around $45 \%$ ) were persons under 70 yr. Particularly noteworthy is that the relative increase in mortality was larger in children up to $14 \mathrm{yr}$ than in any other age group, a feature that has not been reported for any previous heat wave. The large impacts among younger persons contrast to the results of most other studies on age-specific mortality during severe heat waves (including those for the 2003 heat wave in Europe), which often report that mortality effects were confined to or mostly occurred among the elderly.

Thus, enhanced attention should be paid to younger age groups in further epidemiological studies of heat-related mortality. Possible causes of the large effects on mortality in children during the 1994 heat waves in South Korea deserve further investigation regarding relations to the social and demographic structure of the population, health care services and other factors contributing to the lack of physiological and/or behavioural adaptation to heat. The need for more 
research on the effects of heat on mortality and morbidity in children (results for populations in individual cities are very often inconclusive due to small sample sizes) has recently also been pointed out by Ishigami et al. (2008).

The mortality response during the July/August 1994 heat wave was stronger in males than in females (throughout the age groups), despite the finding that males are less vulnerable to heat during 'average' heat waves. Larger excess mortality in males than in females prevailed in some other relatively severe heat waves in Korea (although not comparable to the 1994 event), and may be indicative of a higher threshold level of ambient heat at which physiological disorders appear in males; however, mortality rises more sharply in males when the threshold is exceeded. It is also possible that males are less risk-averse than females and place themselves in more danger during extreme events.

As unusually hot weather continued after the July/ August 1994 heat wave into the second half of August 1994, the total death toll of the 1994 heat waves exceeded 3300 in Korea, a value which is an order of magnitude larger than during any other summer between 1991 and 2005. This finding is independent of the specific settings of the baseline mortality estimation, since several modifications leave the results virtually unchanged. The estimate represents net excess mortality, as no mortality displacement effect appeared. The study also reveals that previous data on the num-

Table 5. Documented large natural disasters (>200 deaths) affecting the Korean Peninsula since 1901 (data from Wikipedia [http://en.wikipedia.org/wiki/List_of_natural_disasters_by_ death_toll, accessed March 5, 2008], except for the 1994 heat waves)

\begin{tabular}{|c|c|c|c|}
\hline Year & Event & $\begin{array}{l}\text { Death } \\
\text { toll }\end{array}$ & $\begin{array}{l}\text { Affected region } \\
\text { for which death } \\
\text { toll is given }\end{array}$ \\
\hline 1994 & Heat waves & 3384 & South Korea \\
\hline 1936 & Typhoon & 1104 & $\begin{array}{l}\text { South, North } \\
\text { Korea }\end{array}$ \\
\hline 2006 & Flooding & 844 & North Korea \\
\hline 1959 & Typhoon Sarah & 768 & $\begin{array}{l}\text { South Korea } \\
\text { and Japan }\end{array}$ \\
\hline 1972 & Seoul, Kyonggi flood & 672 & South Korea \\
\hline 2007 & Flooding & 610 & North Korea \\
\hline 1969 & $\begin{array}{l}\text { Gyeongsangbukdo, } \\
\text { Gyeongsangnamdo, } \\
\text { Gangwon flood and } \\
\text { landslides }\end{array}$ & 408 & South Korea \\
\hline 1987 & $\begin{array}{l}\text { Chungchongnamdo, } \\
\text { Chollanamdo, Kangwon } \\
\text { flood and landslides }\end{array}$ & 345 & South Korea \\
\hline 1998 & $\begin{array}{l}\text { Massive rain, floods and } \\
\text { landslides }\end{array}$ & 324 & South Korea \\
\hline 2002 & Typhoon Rusa & 246 & South Korea \\
\hline
\end{tabular}

ber of victims due to the East Asian 1994 heat waves ('over 1000' in China, Japan and South Korea together according to Wikipedia [http://en.wikipedia.org/wiki/ List_of_natural_disasters_by_death_toll, accessed March $5,2008]$ ) were largely underestimated. The event ranks among the worst heat waves in terms of mortality impacts ever documented around the globe, particularly when the fact that hot weather also affected densely populated parts of China and Japan is taken into account. A comparison with other documented natural disasters affecting the Korean Peninsula (Table 5) emphasises the large death toll of the heat waves, which was much higher than that of the worst incidences of flooding throughout the 20th century. Since the mortality impacts were not confined to the elderly, the number of victims was also larger than in any other natural disaster or large accident (Table 1) over recent decades in South Korea among younger persons, including children. This finding clearly shows that severe heat may be the most deadly of natural hazards, not only for the elderly and/or people whose health has been compromised before the event.

A climatological analysis reveals that the July/August 1994 heat wave over East Asia was clearly exceptional (in terms of its duration and severity), and it might be considered an extremely rare event with a recurrence period on the order of 100 s of years if stationarity of temperature time series is assumed. However, under the general warming trend that has been observed in the area and is projected under climate change scenarios, recurrence probabilities associated with an extreme event comparable to the 1994 heat wave rise sharply. If a warming of $0.04^{\circ} \mathrm{C} \mathrm{yr}^{-1}$ is assumed over the period from 2001 to 2060 , the recurrence interval of a very long spell of days with temperatures exceeding a high threshold (as in the 1994 heat wave) is estimated to decrease to around 40 (10) yr in the period from 2021 to 2030 (2041 to 2050). Although the first-order autoregressive model used for the simulation of daily temperature series may suffer from some drawbacks in the reproduction of day-to-day temperature variability and very long heat waves (which are difficult to be validated against observations due to short records), the sharp rise in the recurrence probability demonstrates that even moderate warming would have a severe impact on the frequency of extreme temperature events. The fact that the model reproduces probabilities of moderate heat waves similar to those calculated with the observed temperature series for Korea also supports the plausibility of the reported increase in occurrence.

However, when estimating possible effects of future heat waves on mortality, the role of adaptation has to be considered. Simple extrapolations do not appear to result in realistic scenarios; although heat waves are 
likely to become longer and more severe, the effects on mortality will depend on ongoing societal changes and adaptations. A decrease in heat-related mortality has been reported in several developed regions, despite ageing populations and the rising trends in temperature extremes (Davis et al. 2003, Donaldson et al. 2003, Carson et al. 2006). Positive socio-economic developments, as well as more reliable forecasting and better public awareness of heat-related risks, are among the factors contributing to the adaptation to heat and mitigation of its impacts.

The presented results highlight the need for interaction and cooperation between meteorologists, public health officers, stakeholders and the public. Improved recognition of stressful weather conditions, namely the development of methods to forecast whether a day will be oppressive or not, and the subsequent implementation of precautionary measures triggered by heatwatch-warning systems, have already decreased the numbers of victims due to heat in many locations (e.g. Ebi et al. 2004, Sheridan \& Kalkstein 2004, Tan et al. 2004, Pascal et al. 2006). An enhanced public perception of heat, leading to a behavioural response, is the key factor in efficiently reducing mortality due to excessive heat. The development of a heat-watchwarning system in South Korea is currently under way (Kalkstein et al. 2008), and the increasing recurrence probability due to global climate change of a heat wave comparable to that in 1994 emphasizes the need for further efforts and better preparation for the risks associated with such extreme weather occurrences.

Acknowledgements. The study was carried out under a joint project supported by the Korea Research Foundation (KRF2006-C00005) and the Czech Science Foundation (205/07/ J044). Thanks are due to the staff of the Korea National Statistical Office, Seoul, for providing daily mortality datasets; 2 anonymous reviewers for comments on the original manuscript; and the other members of the research team for general support and assistance during the work.

\section{LITERATURE CITED}

Alexander LV, Zhang X, Peterson TC, Caesar J and others (2006) Global observed changes in daily climate extremes of temperature and precipitation. J Geophys Res 111:D05109, doi: 10.1029/2005GL023378

> Bae DH, Jung IW, Chang H (2008) Potential changes in Korean water resources estimated by high-resolution climate simulation. Clim Res 35:213-226

Boo KO, Kwon WT, Oh JH, Baek HJ (2004) Response of global warming on regional climate change over Korea: an experiment with the MM5 model. Geophys Res Lett 31: L21206, doi: 10.1029/2004GL021171

Boo KO, Kwon WT, Baek HJ (2006) Change of extreme events of temperature and precipitation over Korea using regional projection of future climate change. Geophys Res Lett 33:L01701, doi: 10.1029/2005JD006290
Carson C, Hajat S, Armstrong B, Wilkinson P (2006) Declining vulnerability to temperature-related mortality in London over the 20th century. Am J Epidemiol 164:77-84

Choi Y (2004) Trends on temperature and precipitation extreme events in Korea. Journal of the Korean Geographical Society 39:711-721

Choi GY, Choi JN, Kwon HJ (2005) The impact of high apparent temperature on the increase of summertime diseaserelated mortality in Seoul: 1991-2000. J Prev Med Pub Health 38:283-290

> Colombo AF, Etkin D, Karney BW (1999) Climate variability and the frequency of extreme temperature events for nine sites across Canada: implications for power usage. J Clim 12:2490-2502

Curriero FC, Heiner KS, Samet JM, Zeger SL, Strug L, Patz JA (2002) Temperature and mortality in 11 cities of the eastern United States. Am J Epidemiol 155:80-87

Davis RE, Knappenberger PC, Novicoff WM, Michaels PJ (2002) Decadal changes in heat-related human mortality in the eastern United States. Clim Res 22:175-184

> Davis RE, Knappenberger PC, Novicoff WM, Michaels PJ (2003) Decadal changes in summer mortality in US cities. Int J Biometeorol 47:166-175

Donaldson GC, Keatinge WR, Näyhä S (2003) Changes in summer temperature and heat-related mortality since 1971 in North Carolina, South Finland, and Southeast England. Environ Res 91:1-7

Ebi K, Teisberg TJ, Kalkstein LS, Robinson L, Weiher RF (2004) Heat watch/warning systems save lives. Bull Am Meteorol Soc 85:1067-1073

Frich P, Alexander LV, Della-Marta P, Gleason B, Haylock M, Klein Tank AMG, Peterson T (2002) Observed coherent changes in climatic extremes during the second half of the 20th century. Clim Res 19:193-212

Gosling SN, McGregor GR, Páldy A (2007) Climate change and heat-related mortality in six cities. Part 1: model construction and validation. Int J Biometeorol 51:525-540

> Guest CS, Wilson K, Woodward AJ, Hennessy K, Kalkstein LS, Skinner C, McMichael AJ (1999) Climate and mortality in Australia: retrospective study, 1979-1990, and predicted impacts in five major cities in 2030. Clim Res 13:1-15

> Hajat S, Kovats RS, Atkinson RW, Haines A (2002) Impact of hot temperatures on death in London: a time series approach. J Epidemiol Community Health 56:367-372

> Huynen MMTE, Martens P, Schram D, Weijenberg MP, Kunst AE (2001) The impact of heat waves and cold spells on mortality rates in the Dutch population. Environ Health Perspect 109:463-470

> Im ES, Ahn JB, Kwon WT, Giorgi F (2008) Multi-decadal scenario simulation over Korea using a one-way doublenested regional climate model system. Part 2. Future climate projection (2021-2050). Clim Dyn 30:239-254

IPCC (International Panel on Climate Change) (2007) Climate change 2007: the physical science basis. Contribution of Working Group I to the IPCC 4th assessment report. Cambridge University Press, Cambridge

Ishigami A, Hajat S, Kovats RS, Bisanti L, Rognoni M, Russo A, Paldy A (2008) An ecological time-series study of heat-related mortality in three European cities. Environ Health 7:5

Kalkstein LS, Sheridan SC, Au YC (2008) A new generation of heat-health warning systems for Seoul and other major Korean cities. Meteorol Tech Policy 1:62-68

Keatinge WR, Donaldson GC, Cordioli E, Martinelli M and others (2000) Heat related mortality in warm and cold regions of Europe: observational study. BMJ 321:670-673 
Kim H, Ha JS, Park J (2006a) High temperature, heat index, and mortality in 6 major cities in South Korea. Arch Environ Occup Health 61:265-270

Kim J, Lee DG, Park IS, Choi BC, Kim JS (2006b) Influences of heat waves on daily mortality in South Korea. Atmosphere (Toronto) 16:269-278 [in Korean with English abstract]

KMA (Korea Meteorological Administration) (1990) Climatological extremes of Korea (1904-1989). KMA, Seoul

Kwon WT (2005) Current status and perspectives of climate change sciences. J Korean Meteorol Soc 41:325-336 [in Korean with English abstract]

Kyselý J (2004) Mortality and displaced mortality during heat waves in the Czech Republic. Int J Biometeorol 49: 91-97

Kyselý J, Huth R (2004) Heat-related mortality in the Czech Republic examined through synoptic and 'traditional' approaches. Clim Res 25:265-274

Laschewski G, Jendritzky G (2002) Effects of the thermal environment on human health: an investigation of 30 years of daily mortality data from SW Germany. Clim Res 21: 91-103

Macchiato M, Serio C, Lapenna V, LaRotonda L (1993) Parametric time series analysis of cold and hot spells in daily temperature: an application in southern Italy. J Appl Meteorol 32:1270-1281

Mearns LO, Katz RW, Schneider SH (1984) Extreme high temperature events: changes in their probabilities with changes in mean temperature. J Clim Appl Meteorol 23: 1601-1608

Meehl GA, Tebaldi C (2004) More intense, more frequent, and longer lasting heat waves in the 21st century. Science 305:994-997

Nakai S, Itoh T, Morimoto T (1999) Deaths from heat stroke in Japan: 1968-1994. Int J Biometeorol 43:124-127

Park CK, Schubert SD (1997) On the nature of the 1994 East Asian summer drought. J Clim 10:1056-1070

Pascal M, Laaidi K, Ledrans M, Baffert E and others (2006) France's heat health watch warning system. Int J Biometeorol 50:144-153

Rooney C, McMichael AJ, Kovats RS, Coleman MP (1998)

Editorial responsibility: Nils Chr. Stenseth,

Oslo, Norway
Excess mortality in England and Wales, and in Greater London, during the 1995 heatwave. J Epidemiol Community Health 52:482-486

Sartor F, Snacken R, Demuth C, Walckiers D (1995) Temperature, ambient ozone levels, and mortality during summer 1994, in Belgium. Environ Res 70:105-113

Sheridan SC, Kalkstein LS (2004) Progress in heat watchwarning system technology. Bull Am Meteorol Soc 85: 1931-1941

Smoyer KE, Kalkstein LS, Greene JS, Ye H (2000a) The impacts of weather and pollution on human mortality in Birmingham, Alabama and Philadelphia, Pennsylvania. Int J Climatol 20:881-897

> Smoyer KE, Rainham DGC, Hewko JN (2000b) Heat-stressrelated mortality in five cities in southern Ontario: 1980-1996. Int J Biometeorol 44:190-197

Steadman RG (1979) The assessment of sultriness. I. A temperature-humidity index based on human physiology and clothing science. J Appl Meteorol 18:861-873

Sung J, Kim H, Cho SH (2001) Summertime heat waves and ozone: an interaction on cardiopulmonary mortality? Based on the 1994 heat wave in Korea. Korean J Prev Med 34:316-322

Tan J, Kalkstein LS, Huang J, Lin S, Yin H, Shao D (2004) An operational heat/health warning system in Shanghai. Int J Biometeorol 48:157-162

Tan J, Zheng Y, Song G, Kalkstein L and others (2007) Heat wave impacts on mortality in Shanghai, 1998 and 2003. Int J Biometeorol 51:193-200

Vaneckova P, Hart MA, Beggs PJ, de Dear RJ (2008) Synoptic analysis of heat-related mortality in Sydney, Australia, 1993-2001. Int J Biometeorol 52:439-451

Wang H, Sekine M, Chen X, Kagamimori S (2002) A study of weekly and seasonal variation of stroke onset. Int J Biometeorol 47:13-20

> Whitman S, Good G, Donoghue ER, Benbow N, Shou WY, Mou SX (1997) Mortality in Chicago attributed to the July 1995 heat wave. Am J Public Health 87:1515-1518

> Yihui D, Chan JCL (2005) The East Asian summer monsoon: an overview. Meteorol Atmos Phys 89:117-142

Submitted: March 17, 2008; Accepted: September 8, 2008 Proofs received from author(s): December 22, 2008 